\title{
Polypharmacy in the HIV-infected older adult population
}

This article was published in the following Dove Press journal:

Clinical Interventions in Aging

20 June 2013

Number of times this article has been viewed

\section{Lauren J Gleason' \\ Amneris E Luque 2 \\ Krupa Shah'}

'Division of Geriatrics and Aging, Highland Hospital, Rochester, NY, USA; ${ }^{2}$ Division of Infectious Disease, Department of Medicine, University of Rochester School of Medicine and Dentistry, Rochester, NY, USA
Correspondence: Krupa Shah Division of Geriatrics and Aging, Highland Hospital, University of Rochester School of Medicine and Dentistry, 1000 South Ave, Rochester, NY 14620, USA

Tel +0I 58434 I 0762

Fax +0I $58434 \mid 8035$

Email krupa_shah@urmc.rochester.edu
Abstract: The prevalence of human immunodeficiency virus (HIV) infection among people older than 50 years is increasing. Older HIV-infected patients are particularly at risk for polypharmacy because they often have multiple comorbidities that require pharmacotherapy. Overall, there is not much known with respect to both the impact of aging on medication use in HIVinfected individuals, and the potential for interactions with highly active antiretroviral therapy (HAART) and coadministered medications and its clinical consequences. In this review, we aim to provide an overview of polypharmacy with a focus on its impact on the HIV-infected older adult population and to also provide some clinical considerations in this high-risk population. Keywords: HIV, older adults, polypharmacy

\section{Introduction: HIV, aging, and comorbidities}

Acquired immunodeficiency syndrome (AIDS)-related mortality of human immunodeficiency virus (HIV)-infected people in the United States has been reduced over the years, and this trend is in large part a result of the introduction of highly active antiretroviral therapy (HAART). ${ }^{1}$ As a result, HIV-infected individuals are living longer. By 2015, more than one-half of all HIV-infected individuals in the United States will be older than 50 years of age. ${ }^{2}$ The prevalence of HIV in this age group is expected to be significant considering the increased life expectancy of the general population and the increased survival of HIV-infected individuals. In the general population, those who are 50 years and older are not referred to as "older adults." However, in the HIV/ AIDS population, this subset of the population does carry the label "older adults." The Centers for Disease Control and Prevention applies this label and considers this subset of the population as a separate group, mainly because early in the HIV epidemic, this age group was much older than the mean age of HIV-infected patients. ${ }^{2}$

Studies have shown that in the current environment, where the number of HIVinfected older adults has continued to increase year after year, there has been a similar increase in the number of comorbid conditions concomitantly present in these individuals and also an increased use of medications. In one study that investigated HIV-infected individuals aged 55 years and older in New York City, 89\% had one or more comorbidities, or an average of 2.4 comorbid conditions per person, and $81 \%$ received medications unrelated to $\mathrm{HIV}^{3}$ In that study, the most common comorbidities were hypertension, chronic obstructive pulmonary disease, and diabetes mellitus.

Additionally, it is believed that HIV infection, and quite possibly its treatment, may be contributing to the acceleration of the aging process by several years when compared 
with those who are not infected with HIV. Dyslipidemia, dysregulation of glucose metabolism, reduced bone density and osteopenia, hypogonadism, renal and hepatic disorders, psychiatric illness, neurocognitive impairment, and coronary artery disease are all conditions likely to occur earlier in HIV-infected individuals compared with their unaffected peers. ${ }^{4}$ Another study that compared HIV-infected veterans 50 years of age and older to non-HIV-infected veterans of similar age found that the older HIV-infected veterans had higher odds of multimorbidity. ${ }^{5}$ This study also concluded that when compared to non-HIV infected individuals, the HIV-infected veterans experienced a more pronounced increase in disease burden (hypertension, diabetes mellitus, vascular, pulmonary, and renal disease) as well as an increase disease prevalence as they aged.

A signature collaboration group with cohorts spanning the world was formed to provide information about the prognosis of individuals starting HAART for the first time. The Antiretroviral Therapy (ART) Cohort Collaboration looked at specific causes of mortality of HIV-infected individuals who initiated HAART. They discovered that deaths classified as AIDS-related decreased with increasing duration of HAART therapy. Older age ( $\geq 50$ years) was strongly associated with increased rates of non-AIDS-related malignancy and cardiovascular disease (CAD), and the cause of death least associated with age was AIDS. Furthermore, there was a marked increase in the rates of renal death in patients $>60$ years old. The abovementioned results further demonstrate the burden of chronic comorbid diseases in this population.

As a result of the increased average age of HIV-infected individuals since the introduction of HAART, patients are more often exposed to disease- and treatment-related morbidities, which in turn has led to an increased likelihood of polypharmacy. ${ }^{6}$ Overall, there is not much known about the impact of aging on medication use in HIV-infected individuals; the potential for interactions with HAART and coadministered medications; and the impact of these factors on therapy tolerability and virological response.

\section{Overview of polypharmacy}

Polypharmacy can be simply defined as the concomitant use of multiple medications $;{ }^{7}$ however, polypharmacy also has multiple definitions within the scientific literature such as the use of a large number of medications, the use of potentially inappropriate medications, medication underuse, and medication duplication. ${ }^{8,9}$ The two most commonly cited definitions are more specific and are: (1) the use of six or more medications; or (2) the use of a potentially inappropriate drug for which the medication does not match the diagnosis. ${ }^{10}$
The use of multiple medications is certainly a relevant issue, especially in the older adult population. A national survey by Kaufman et $\mathrm{al}^{11}$ found that $90 \%$ of people aged 65 and older use at least one medication per week, more than $40 \%$ of this population use five or more different medications per week, and $12 \%$ of this population use ten or more medications. Noteworthy, in the same population class, the authors found a $14 \%$ increase in fall risk with the addition of any additional medication after four drugs, regardless of drug class. ${ }^{12}$ Studies have shown that the frequency of unnecessary or not recommended medication use is higher in patients who take many medications compared with those who take few medications. ${ }^{13,14}$

It is important to note some of the negative consequences as a result of polypharmacy. To start, patients taking multiple drugs for multiple chronic medical conditions have a potentially increased risk of falls, ${ }^{12}$ drug-drug interactions (DDIs), and adverse drug events (ADEs). ${ }^{15,16}$ ADEs and DDIs in older adults not only increase morbidity and mortality, ${ }^{15}$ but they also are a common cause of emergency hospitalizations and represent common occurrences in both the hospital and ambulatory settings. ${ }^{17,18}$ An example of an ADE with polypharmacy is the increased risk of serious hypoglycemia when prescribed sulfonylureas or insulin therapy with the use of five or more therapeutic classes. ${ }^{19}$ Drug interactions can also be associated with an increased risk of toxicity. Some common interactions include combining digoxin with diuretics, resulting in digoxin toxicity including arrhythmias and hyperkalemia; the use of nonsteroidal antiinflammatory drugs and diuretics resulting in renal failure; and combinations or narcotics and antidepressants causing central nervous system depression and sedation. ${ }^{20}$ That being said, the identification and the management of such interactions are absolutely important for delivering quality patient care.

It has been reported that ADEs are common and often preventable in older adults in the ambulatory setting. The rate of ADEs was 50.1 per 1000 person-years; 28\% of ADEs were found to be preventable. ${ }^{21}$ Field et $\mathrm{al}^{22}$ conducted a large nested case control study in an ambulatory population and found that there was a dose-response association of ADEs with the Charlson Comorbidity Index score and number of scheduled medications. In the analysis of preventable ADEs, the dose-response relationship with comorbidity and number of medications persisted. Patients taking anticoagulants, antidepressants, antibiotics, cardiovascular drugs, diuretics, hormones, and corticosteroids were at increased risk for ADEs. Moreover, patients at greatest risk from polypharmacy were those who saw several doctors, had prescriptions filled 
at multiple pharmacies, and were older adults with multiple comorbidities. $^{23,24}$

Polypharmacy can be linked to increased costs for both the patient and the health care system. Some of the medications older patients take, including over-the-counter medications, are often not covered by health insurance or Medicare. The result can be an increased financial burden for older patients whose income generally consists of using savings from a retirement account and a fixed income such as Social Security. ${ }^{25}$ Not surprisingly, a study that compared two groups of Medicare patients found there was a statistically significant difference in statin use when comparing those with prescription drug coverage to those without prescription drug benefits $(27.4 \%$ versus $4.1 \%){ }^{26}$

Additionally, minor drug interactions can lead to increased clinic visits, a prescribing cascade where additional medications are given to treat new symptoms, or new lab or imaging studies. Serious adverse events from polypharmacy can lead to specialist visits, emergency department visits, and hospital admissions. ${ }^{17,27,28}$ In a study from the 2000-2001 Medical Expenditure Panel Survey, it was found that the estimated total cost attributed to the use of potentially inappropriate medications in community-dwelling older adults was $\$ 7.2$ billion. $^{29}$

There are two approaches to evaluate potentially inappropriate medication use in older adults: the Beers criteria and the Medication Appropriateness Index. The initial Beers criteria in 1991 consisted of lists of specific drugs or drug classes that were considered inappropriate based on preexisting conditions for nursing home residents; the list was expanded to include all settings of geriatric care in 1997, 2003, and 2012. ${ }^{30-33}$ The Medication Appropriateness Index uses ten items to assess the degree of appropriateness of a particular medication along with a three-point Likert rating scale. ${ }^{34}$ Inappropriate medication use in the ambulatory setting has been shown to be prevalent in $65 \%$ of older adults, ${ }^{35}$ but concomitantly, these same patients are often not prescribed potentially beneficial medications. $^{9}$

Another problem with a large number of medications being prescribed is the increase in "pill burden," which can potentially affect compliance because patients simply get tired of taking their medications and miss doses as a result. Most of the literature that examines dosing regimens and compliance has been conducted in the HIV-infected population in which nearly perfect adherence is required to achieve and sustain viral suppression, maintain immune health, and slow disease progression. ${ }^{36}$ Not surprisingly, literature on the relationship of regimen factors and adherence in HIV disease indicates that higher dose frequency and greater regimen complexity result in poorer adherence. ${ }^{36}$

\section{Polypharmacy in HIV-infected patients}

Polypharmacy is common in the HIV-infected older adult population. Marzolini et $\mathrm{al}^{37}$ in a Swiss cohort study compared HIV-infected older adults who were aged $\geq 50$ years with younger HIV-infected patients (aged $<50$ ) on HAART; they found that older patients were more likely to receive one or more comedications compared with younger patients ( $82 \%$ versus $61 \%, P<0.001)$. This study also determined that older patients had more frequent potential for DDIs when compared with the younger patients $(51 \%$ versus $35 \%, P<0.001)$. Furthermore, HIV-infected older adults generally used a higher number of comedications and certain therapeutic drug classes more frequently when compared with the HIV-infected younger patients. Some of the drugs studied were cardiovascular drugs (53\% in the older group versus $19 \%$ in the younger group), gastrointestinal medications ( $10 \%$ versus $6 \%$ ), and hormonal agents ( $6 \%$ versus $3 \%$ ). The potential for DDIs with HAART in the older adult group occurred mainly with cardiovascular drugs (27\%), central nervous system agents (22\%), and methadone (6\%). It should be noted, however, that medications used in the older patient group and the younger patient group were not significantly different with respect to the effect on antiretroviral tolerability and response. ${ }^{37}$ Another study reviewed the prevalence and risk factors for clinically significant drug interactions with HAART, and it was found that those subjects aged $>42$ years with more than three comorbidities and a treatment plan consisting of three or more antiretroviral agents or a protease inhibitor (PI) were at an independently increased risk of a clinically significant drug interaction. ${ }^{38} \mathrm{It}$ has been shown that HIV-infected patients aged 50 years or older have a better adherence rate to HAART treatment than their younger counterparts; ${ }^{39-42}$ as a result, this can increase the likelihood of potential drug interactions.

There are currently six classes of antiretroviral medications approved for use in the United States and these include nucleoside reverse transcriptase inhibitors, nonnucleoside reverse transcriptase inhibitors (NNRTIs), PIs, integrase inhibitors, fusion inhibitors, and CCR5 antagonists. ${ }^{43}$ Treatment with HAART has the potential for DDIs. As a class effect, PIs can inhibit cytochrome P450 3 A (CYP3 A) to varying degrees and to some extent other isoenzymes, with ritonavir (RTV) being the most potent. ${ }^{44} 46$ RTV is used to "boost" the levels of other PIs by inhibiting their metabolism. 
Inhibition of CYP450 (CYP3 A) can cause an increased plasma concentration of CYP450 CYP3 A substrates, either antiretroviral or nonantiretroviral, which has the potential for toxicity. On the contrary, NNRTIs such as nevirapine, efavirenz, etravirine, and PIs, such as lopinavir and tipranavir, are inducers of CYP3 A, which can lower the concentration of some CYP3 A substrates. ${ }^{47}$ Interactions involving efavirenz, nevirapine, etravirine, and other medications that are metabolized through CYP450 3 A4 can lead to decreased plasma concentrations of coadministered medications, potentially leading to their decreased efficacy. Nucleoside reverse transcriptase inhibitors, maraviroc, raltegravir, and enfuvirtide do not inhibit or induce CYP450 isoenzymes, and clinically significant DDIs with these medications are uncommon. ${ }^{48}$

The combination of HAART and polypharmacy significantly increases the chance of adverse outcomes stemming from the potential DDIs. Some of these negative outcomes include drug toxicity, poorer HAART adherence, loss of efficacy of the coadministered medication, and virologic breakthrough.

\section{Consequences of polypharmacy in older HIV-infected patients}

The consequences of polypharmacy are significant in older adults infected with HIV. Of note, the combination of medications used to treat chronic diseases and HAART in older adults infected with HIV increases the chance for DDIs, which can lead to the loss of efficacy of medications and toxicity. Older adults are even more susceptible to drug interactions than their younger counterparts. First, older adults infected with HIV suffer from aging-related comorbid illness. Second, age-related physiologic changes affect the pharmacokinetic and pharmacodynamic properties of medications. These physiologic changes can be explained by a number of factors including patient genetics, lifestyle, and their specific environment. Simultaneously, these changes contribute to interpatient variability and may add complexity to the management of drug interactions in our older adult population. Pharmacokinetic alterations with aging alone can result in changes to both a person's body composition and to the function of drug-eliminating organs. For example, lipophilic drugs in combination with the normal age-related changes to the patient's body composition (eg, the increased proportion of fat mass with loss of lean mass and decreased total body water) tend to result in an increased volume of distribution and a prolonged half-life, whereas water-soluble drugs tend to have a decreased volume of distribution. ${ }^{49}$
Hepatic metabolism and renal elimination are major routes of drug clearance, including the clearance of HAART. Some age-related changes include a decline in liver and renal function, which may result in impaired drug elimination and drug accumulation. ${ }^{50}$ Liver volume and hepatic blood flow decrease with increasing age. ${ }^{51,52}$ This relationship needs to be taken into account when prescribing potentially hepatotoxic agents, such as the majority of PIs and NNRTIs. ${ }^{53}$ Given the hepatotoxicity with multidrug HAART and potential interactions with other medications including lipid lower agents, over-the-counter medications, and antituberculosis therapy, it is important to monitor liver function in older adults with HIV. ${ }^{54}$

Additionally, on average in adults, the glomerular filtration rate decreases about $1 \%$ per year with increasing age ${ }^{55}$ and the methods for estimating renal function may overestimate this function in older adults by not taking their lowered relative muscle mass into account. ${ }^{56}$ In older adults with HIV, this problem is further complicated because this population characteristically has lower muscle mass than their counterparts and often, confounding factors that can further decrease renal function - diabetes mellitus, hypertension, low CD4 cell count, race, and use of the antiretrovirals tenofovir and indinavir. ${ }^{57-60}$ Estimating renal function is therefore even more difficult in HIV-infected older adults and affects the dosing and prescription of renally excreted medications. For example, cobicistat reduces the apparent estimated glomerular filtration rate by $15 \%$ on the initiation of treatment with this drug as a result of reduced tubular excretion of creatinine. ${ }^{61,62}$

Significant DDIs between HAART and various important drug classes are summarized in Table 1. The actual prevalence of ADEs and DDIs in the HIV-infected older adults is not known. Indeed, most of the studies that have been conducted with respect to antiretroviral metabolism have excluded subjects of advanced age with comorbid disease. In short, there is little data on the toxicities of antiretrovirals, especially with respect to HIV-infected older adults. More targeted research is needed.

\section{Drug-drug interactions by system}

\section{Cardiovascular medications}

$\mathrm{CAD}$ is one of the most common comorbidities in the aging $\mathrm{HIV}$-infected population, and cardiovascular drugs are the most frequently prescribed medications in this population. ${ }^{37}$ CAD prevalence in this population is likely due to a combination of factors including increasing age and habits such as tobacco use, as well as toxicity from HAART. ${ }^{63}$ 


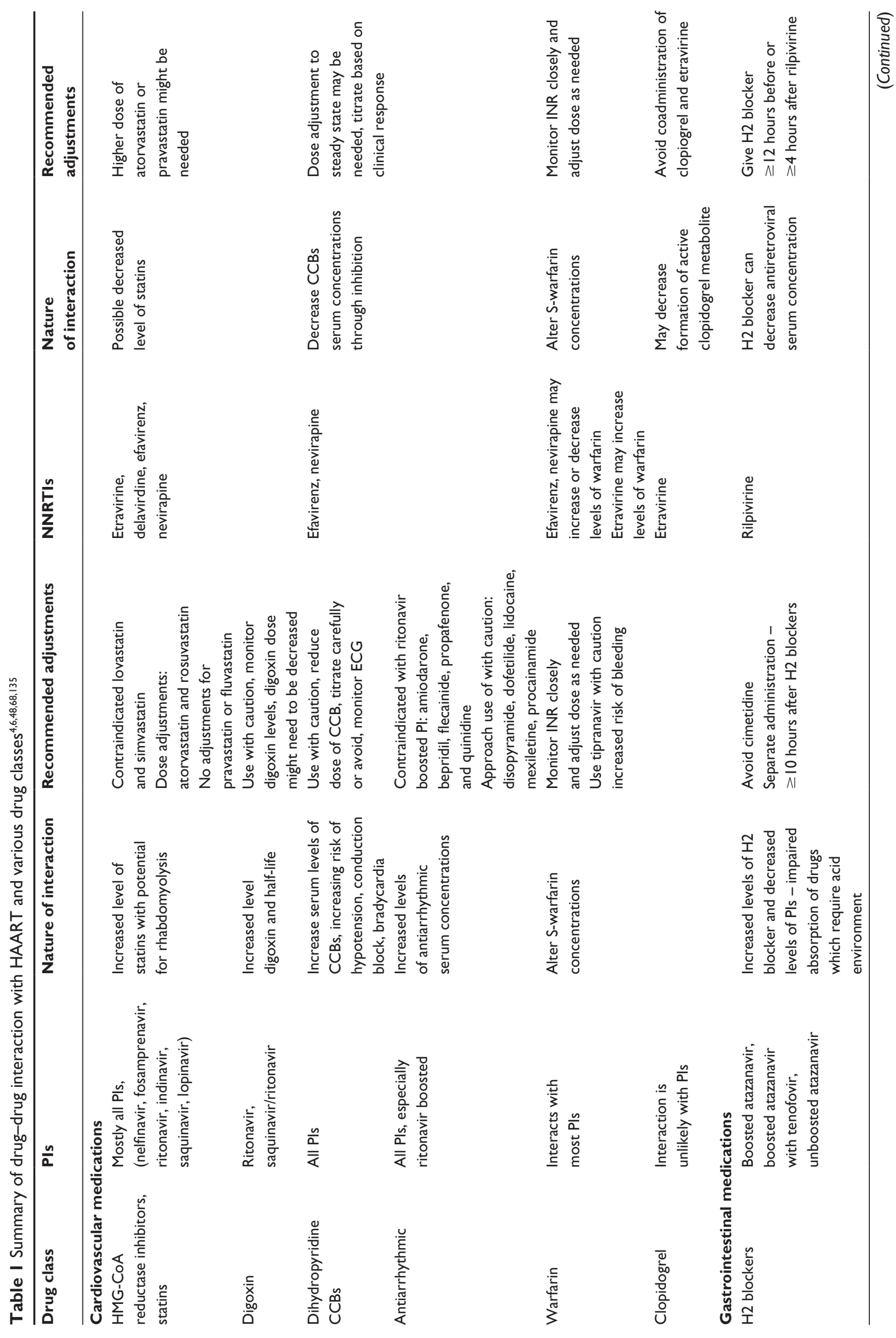




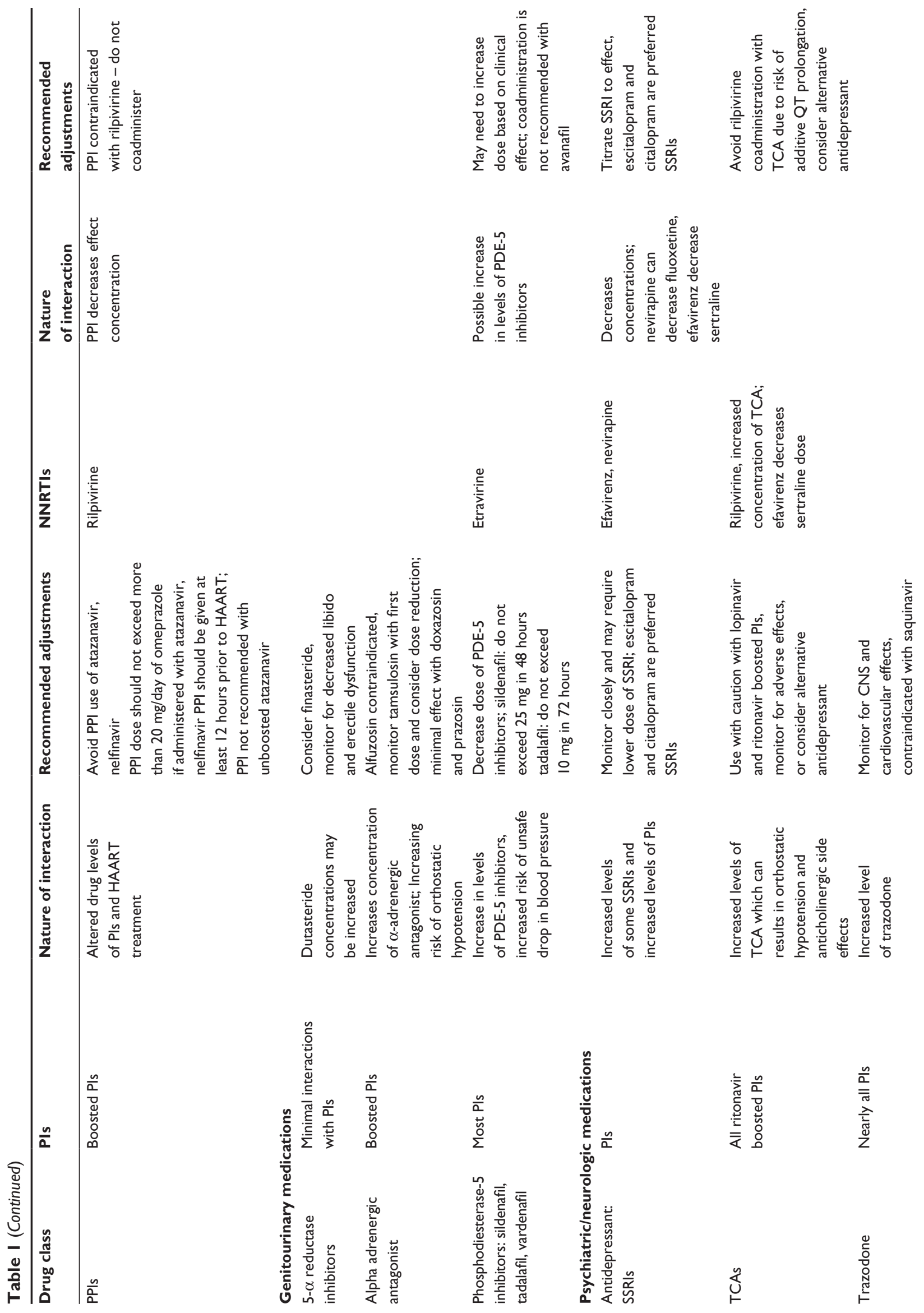




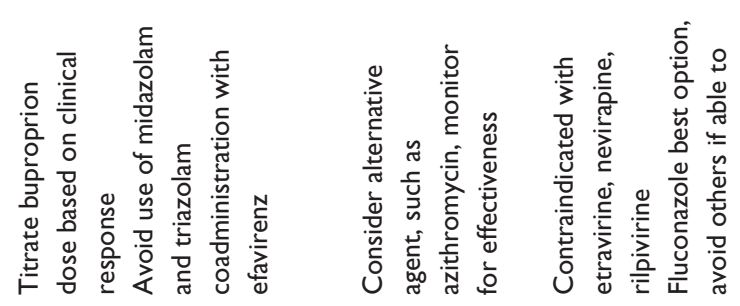

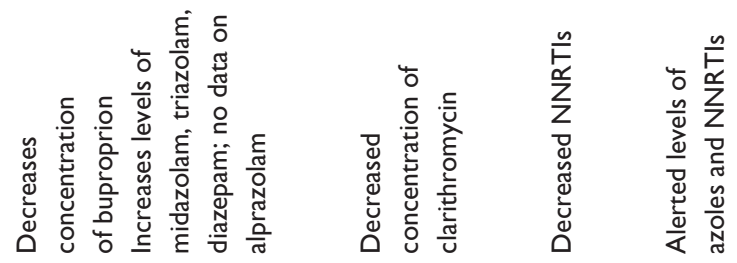

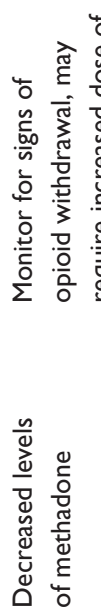

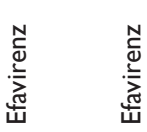
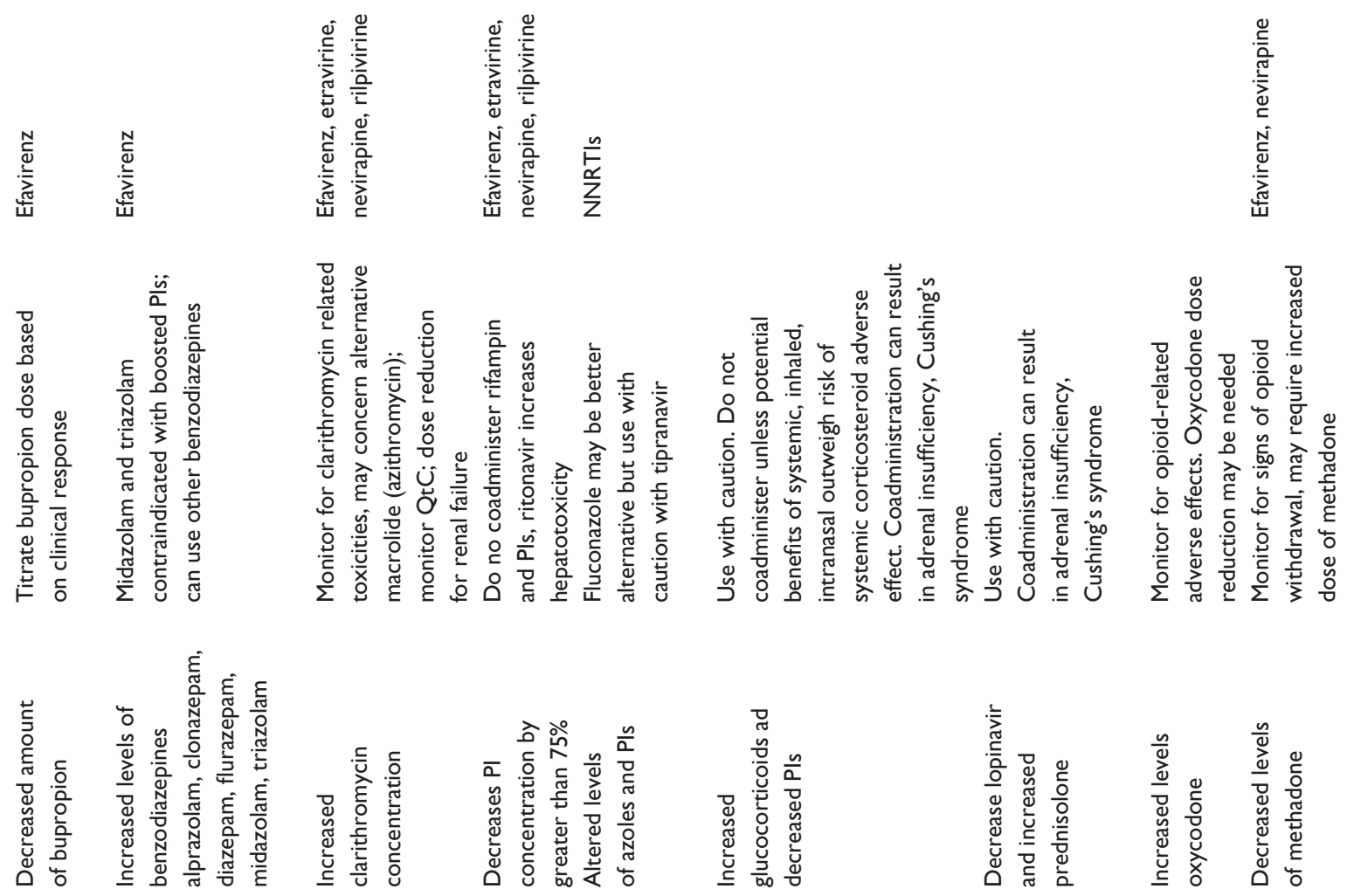

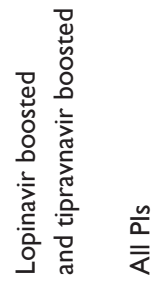

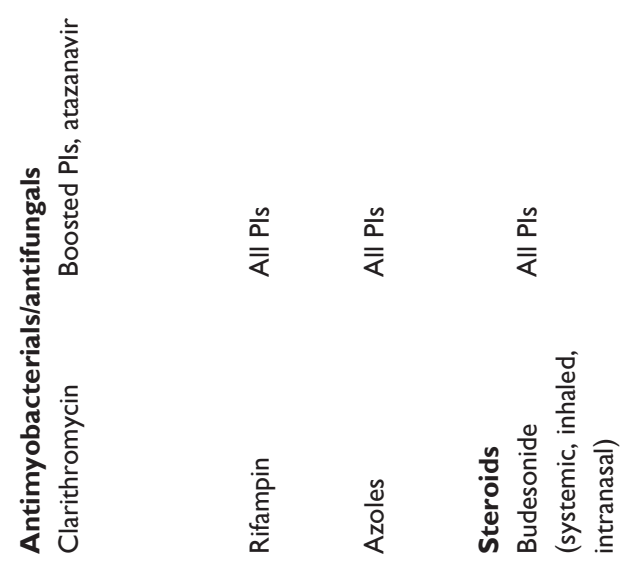


Prolonged treatment with HAART has been shown to be associated with an increased prevalence of hypertension in HIV-infected individuals and also with elevated blood pressure ${ }^{64}$ which may be seen in association with the fat redistribution/lipodystrophy syndrome..$^{65,66}$

Hypertension is an important modifiable cardiac risk factor in HIV-infected patients; treating those who are older and on HAART can be challenging. Dihydropyridine calcium channel blockers (CCBs) have been shown to interact with HAART. Boosted PIs may increase the concentration of CCB in the serum and can potentially prolong the heart's PR interval, thus causing first-degree heart block and augment the hypotensive effect. ${ }^{67}$ However, NNRTIs such as efavirenz and nevirapine can have the opposite effect on medication levels and have been shown to decrease CCB serum concentrations; this may require further dose adjustments to achieve a steady state. ${ }^{68}$ Diltiazem area under the curve (AUC) is increased $125 \%$ by atazanavir; if coadministering these medications, the diltiazem dose should be reduced by $50 \%$ and electrocardiography monitoring is recommended. It is possible that other PIs increase the levels of diltiazem; therefore, they should be used with caution and the diltiazem dose adjusted to clinical response and toxicities. ${ }^{68}$

The antiarrhythmic agents, amiodarone and dronedarone (class 3 antiarrhythmics), are contraindicated in patients receiving PIs. As potent CYP3 A4 inhibitors, PIs have the potential to significantly reduce the metabolism of these agents and can cause serious and life-threatening adverse events. The concurrent use of lidocaine and saquinavir is contraindicated because saquinavir may increase the serum concentration of lidocaine, and therefore, its arrhythmogenic effect. ${ }^{68}$

Digoxin is prescribed for conditions that are common in older adults, including heart failure and atrial fibrillation with a rapid ventricular rate. ${ }^{69}$ Between $60 \%$ and $80 \%$ of digoxin is eliminated by the kidneys. ${ }^{70}$ Therefore, those older patients with HIV who have an increased risk of chronic kidney disease and also low body mass older patients are often subject to an increased risk of toxicity. For this reason, close monitoring of digoxin serum concentration in older HIV-infected individuals is crucial. Saquinavir/RTV increases the digoxin AUC about 49\%, and this is most likely via P-glycoprotein inhibition. Given the relatively narrow therapeutic window of digoxin, caution should be exercised when these drugs are administered together. ${ }^{68}$ It has been recommended that digoxin doses be reduced and that digoxin serum concentrations be monitored. ${ }^{71}$
Warfarin is known to interact with many drugs through a variety of mechanisms. NNRTIs and PIs are the antiretrovirals most likely to interact with warfarin. Among the NNRTIs, induction of warfarin metabolism is likely with nevirapine. The inhibition of warfarin metabolism can occur with efavirenz, delavirdine, or etravirine coadministration. Interactions with PIs, such as RTV, are also common. ${ }^{72}$ Liedtke and Rathbun ${ }^{43}$ have concluded that patients on warfarin and antiretrovirals need close international normalized ratio monitoring, and also that empiric warfarin dosage adjustments are difficult to recommend given the limited clinical evidence available and the absence of formal pharmacokinetic studies for most agents.

HAART treatment has not only been correlated with increased CAD, but also with increases in total cholesterol levels and triglyceride levels. ${ }^{73}$ Significant DDIs have been reported between antiretrovirals and agents prescribed to treat hyperlipidemia. Simvastatin and lovastatin, which are metabolized via the cytochrome P-450 system, are contraindicated with any PI. Low-dose pravastatin, atorvastatin, or rosuvastatin are recommended. These agents can be titrated up as needed. ${ }^{4}$ Atorvastatin should not exceed $20 \mathrm{mg}$ daily when used with darunavir/RTV, fosamprenavir/RTV, saquinavir/RTV, or fosamprenavir. Atorvastatin is contraindicated with tipranavir. ${ }^{74,75}$

No dose adjustment is necessary for pitavastatin when used with PIs. The rosuvastatin AUC is increased 48\% with darunavir/RTV and the peak concentrations to $139 \%$; therefore, the dose of rosuvastatin must be titrated carefully and the lowest necessary dose used, along with careful monitoring for toxicities. The lipid-lowering benefits of rosuvastatin may be blunted when used in combination with darunavir/RTV. ${ }^{76}$ Pravastatin AUC is also increased $81 \%$ by concurrent use of darunavir/RTV, requiring the use of the lowest possible dose of pravastatin and careful monitoring. ${ }^{77}$ Additionally, efavirenz has been shown to be associated with reduced inhibition of 5-hydroxy-3-methylglutaryl-coenzyme A reductase activity during coadministration with simvastatin, atorvastatin, and pravastatin. ${ }^{78}$

\section{Genitourinary medications}

Benign prostatic hypertrophy $(\mathrm{BPH})$ is common as men age. ${ }^{79}$ Biopsy-proven BPH prevalence increases from $40 \%$ to $50 \%$ in men aged $51-60$ years, and this rate exceeds $80 \%$ in men older than 80 years. ${ }^{80} \mathrm{BPH}$ has been shown to have a substantial negative effect on quality of life, with symptoms that interfere with activities of daily living. ${ }^{81}$ Medications used to treat BPH can interact with antiretrovirals in the 
aging HIV population. PIs may significantly increase concentrations of $\alpha$-adrenergic antagonists such as alfuzosin. Coadministration is not recommended, given increased risk of orthostatic hypotension. Also, boosted PIs with RTV may increase the dose concentration of tamsulosin, and concurrent use is not recommended.$^{82}$ Fewer interactions are expected between PIs and other $\alpha$-antagonists such as doxazosin and prazosin; however, close monitoring is recommended.

Erectile dysfunction has been reported to be a common problem in HIV-infected men. Studies have reported a prevalence rate between $53 \%$ and $71 \%{ }^{83}$ Caution should be exerted with concomitant use of PI and erectile dysfunction drugs such as sildenafil, given the potential for PIs to increase the levels of sildenafil. ${ }^{6,84}$ Sildenafil should be started at $25 \mathrm{mg}$ every 48 hours and monitored for adverse events. The starting dose of tadalafil, also prescribed for erectile dysfunction, should be $5 \mathrm{mg}$ such that it does not exceed a single dose of $10 \mathrm{mg}$ in a 72-hour period. Monitoring for adverse effects of tadalafil, such as hypotension, is recommended. ${ }^{85}$

\section{Gastrointestinal medications}

Interactions between HAART and acid-reducing medications are common in older adults. In older HIV-infected patients treated with HAART, an increased frequency of reflux symptoms, gastroesophageal reflux disease, and H. pylori infection has been observed. ${ }^{86}$ That being said, the treatment of reflux diseases can be problematic because some HAART medications require an acidic environment. The coadministration of $\mathrm{H}-2$ receptor antagonists and atazanavir/RTV in HIV-infected patients has been shown to reduce the effect of atazanavir by approximately $20 \%$. The dose of $\mathrm{H}-2$ receptor antagonist should not exceed the equivalent of $40 \mathrm{mg}$ of famotidine twice daily in those naïve to antiretroviral medications, or $20 \mathrm{mg}$ twice daily in antiretroviral-experienced patients. ${ }^{68}$ Atazanavir should be administered more than 10 hours after the $\mathrm{H}-2$ receptor antagonist. ${ }^{87}$ Proton pump inhibitors (PPIs) should not exceed a dose equivalent to omeprazole $20 \mathrm{mg}$ daily in PI-naïve patients. PPIs should be administered 12 hours before atazanavir/RTV. PPIs are not recommended in patients receiving unboosted atazanavir. ${ }^{88}$ PPIs increase the AUC of saquinavir by $82 \%$. When using these medications concomitantly, it is necessary to monitor for saquinavir toxicity. ${ }^{89}$ Rilpivirine needs an acidic environment for absorption, and $\mathrm{H}-2$ receptor antagonists as well as PPIs can decrease its absorption. ${ }^{68}$

\section{Psychiatric medications}

As many as $10 \%$ of adults 60 years of age or older who are seen in primary care settings have clinically significant depression..$^{90}$
Additionally, major depressive disorder has been shown to be twice as likely to occur in patients with HIV as in those who do not have HIV infection..$^{91}$ Understandably, depression is very common in older adults with HIV. Selective serotonin reuptake inhibitors are often the prescribed treatment for depression in HIV-infected individuals, ${ }^{92}$ and these inhibitors are believed to be better tolerated than tricyclic antidepressants (TCAs).$^{93}$ It is expected that all boosted PIs increase the levels of TCAs: the use of the lowest possible dose of the TCA and monitoring of drug levels are recommended ${ }^{68}$ Escitalopram and citalopram are often the preferred selective serotonin reuptake inhibitors. The AUC of paroxetine is decreased by the concurrent use of boosted darunavir and fosamprenavir, ${ }^{94}$ and titration of the paroxetine dose based on clinical response is recommended.

Trazodone levels increase with the use of unboosted atazanavir and all boosted PIs, thereby increasing the risk for central nervous system and cardiovascular adverse events. ${ }^{95}$ Using the lowest dose of trazodone and monitoring for adverse events is recommended. The combination of lopinavir/RTV and bupropion results in a decrease in the bupropion $\mathrm{AUC}$ and requires titration of the bupropion dose based on clinical response. ${ }^{96}$

Midazolam and triazolam are contraindicated with all PIs. ${ }^{97-100}$ Several commonly used benzodiazepines are metabolized by CYP3 A4. These include alprazolam, clonazepam, diazepam, and flunitrazepam: CYP3 A4 inhibitors cause their levels to rise, resulting in possible toxicities such as over-sedation and central nervous system depression. RTV has been shown to increase blood levels and effects of the benzodiazepine and CYP3 A4 substrate alprazolam. ${ }^{100}$

\section{Antimicrobials/antifungals}

The coadministration of CYP3 A4 inhibitors results in an increased drug exposure to macrolides such as clarithromycin and erythromycin, and this can cause prolonged QTc. ${ }^{101,102}$ QTc prolongation may lead to torsades de pointes, and older adults are particularly at increased risk for this life-threatening arrhythmia. The clarithromycin AUC can increase $94 \%$ with the concurrent use of atazanavir/RTV, thus leading to prolonged QTc; the clarithromycin dose should be reduced by $50 \%$ or an alternative antibiotic considered. The same recommendation applies for the concurrent use of clarithromycin with all other boosted PIs because they also may cause an increase in clarithromycin. Another antimicrobial to be aware of is rifampin, which is a potent inducer of both cytochrome P-450 oxidative enzymes and the $\mathrm{P}$-glycoprotein transport system. Rifampin is contraindicated 
with all PIs because it reduces the therapeutic response and can result in therapeutic failure or a toxic reaction. ${ }^{103}$

The azole antifungals have long been described as potentially arrhythmogenic drugs. ${ }^{104}$ The coadministration with other compounds that inhibit CYP3 A4 may have an additive effect, potentially leading to arrhythmias. When boosted PIs are to be used concomitantly with itraconazole, monitoring levels of the antifungal is advised to guide dosage adjustments; high doses (>200 mg/day) of itraconazole are not recommended. Voriconazole should not be administered with boosted PIs because they decrease the voriconazole AUC. Unboosted atazanavir and fosamprenavir could possibly cause increases on voriconazole; therefore, monitoring for toxicities is necessary. Posaconazole causes increases in the AUC of atazanavir (both boosted and unboosted); therefore, patients who are receiving this combination should be monitored for atazanavir adverse events. In addition, because of decreased posaconazole exposure, coadministration with efavirenz should be avoided unless the benefit to patients outweighs the risk. ${ }^{105}$ The use of high doses of fluconazole with tipranavir is not recommended. No dose adjustment of fluconazole is necessary with boosted atazanavir or saquinavir.

\section{Systemic and inhaled steroids}

The use of systemic, intranasal, or inhaled budesonide in combination with PIs is not recommended unless the potential benefits outweigh the risks, because this combination may result in decreased levels of PIs and an increase in glucocorticoids that can result in Cushing's syndrome. ${ }^{106,107}$ Similarly, inhaled or intranasal fluticasone or systemic prednisone in combination with any boosted PI should be avoided, because it can result in adrenal insufficiency and Cushing's syndrome. ${ }^{108}$ The use of dexamethasone can cause a decrease in the levels of PIs and should therefore be used with caution.

\section{Narcotic pain medications}

Opioids are often used to treat pain in older patients to improve quality of life and function. The concurrent use of lopinavir/ RTV increases the oxycodone AUC 2.6-fold. A reduction in the dose of oxycodone may be needed in addition to close monitoring for adverse opioid effects that indicate it may be necessary to reduce the oxycodone dose. ${ }^{109}$ Boosted atazanavir, darunavir, and fosamprenavir cause a 16\%-18\% decrease in the methadone AUC, whereas lopinavir/RTV decreases the methadone AUC 26\%-53\% and saquinavir/ RTV decreases it $19 \%$. As a result, the concomitant use of boosted PI and methadone may cause opioid withdrawal such that the dose of methadone may need to be increased, in particular with higher reductions in AUC. ${ }^{110-113}$

\section{Osteoporosis therapies}

Osteoporosis is common in HIV-infected persons and has a threefold higher prevalence compared with HIV-negative individuals. ${ }^{114}$ The etiology of osteoporosis in HIV-infected patients is likely multifactorial, involving traditional risk factors as well as the direct effects of chronic HIV infection and antiretroviral therapy. ${ }^{115}$ Emerging evidence suggests that the increase in the prevalence of osteoporosis in HIV-infected persons translates into a higher risk for fracture. ${ }^{116,117}$ As a result, it likely leads to excess morbidity and mortality as the HIV-infected patient ages. Bisphosphonates are generally considered first-line therapy for persons with a history of fragility fracture and/or osteoporosis as diagnosed by dual-energy X-ray absorptiometry. Both alendronate and zoledronic acid have been shown in randomized controlled trials to significantly improve bone mineral density at the lumbar spine and total hip in HIV-infected patients treated for 96 weeks, with no known DDIs between the bisphosphonates and HAART. ${ }^{118,119}$

\section{Clinical considerations for polypharmacy}

A thorough review of medications is absolutely essential when managing HIV-infected older adults. It should be protocol for the health care provider to perform an annual medication reconciliation and a medication review at every visit, especially after hospital stays: hospital admission is a known risk factor for using an increased number of both appropriate and inappropriate medications. ${ }^{120}$ Following such a protocol will help generate a complete and accurate list of active medications that is useful and readily available.

Indeed, when looking at the general population, discrepancies have been noted in the following domains: what medications patients should be taking; what medications they are actually taking; and what physicians have recorded in the patients' records. ${ }^{121}$ Additionally, in a survey of Medicare beneficiaries, more than $35 \%$ of patients reported that they had not spoken with their doctor in the past 12 months about their different medications. ${ }^{122}$ This should be of concern to clinical providers and provides a reason to consider changing the routine protocol.

In the ambulatory setting, there is little direct evidence to support any one method of medication review as superior to another. ${ }^{123}$ Even so, a method that has been advocated for is the "brown bag" review. In the "brown bag" review, patients are asked to bring all their medications to the 
office, including prescription medications, over-the-counter medications, vitamins, and herbal preparations. This method helps start a conversation and provides a clear picture of the patient's most up-to-date medication use. ${ }^{124}$

Once all of the patient's medications have been reconciled, it is helpful to review an array of issues, including: adherence to medication; the indications for medication; the effectiveness of the medication; and the patient's tolerance of the medication. Patients are often reluctant to admit to nonadherence, ${ }^{125}$ and clues can be obtained from observing medication organization, pill counts, and refill history. ${ }^{124}$ Barriers to nonadherence include patients' forgetting to take their pills, not believing the drug is effective, and having difficulty taking or tolerating the pills. Additionally, the cost of medications might also be limiting adherence. It may be appropriate for the clinical provider to answer questions from the patient and to reassure them concerning the effectiveness of any given medication to increase compliance. ${ }^{124}$

Health care providers are often hesitant to stop medications, especially if they did not initiate the treatment. The decision to discontinue a medication is multifactorial and should take into account the indication for the medication, the interaction of the medication with other prescribed medications, tolerance of the medication, and the patient's goals of care as well. Treatment targets are very often derived from studies completed in younger and healthier patients, and there is often little evidence to guide prescription in older adults with multimorbidity. ${ }^{126}$

To summarize, it is extremely important to have a complete and accurate medication history prior to starting additional medications (Table 2). When prescribing a new medication, health care providers should be careful to choose the drug with the highest therapeutic ratio provided efficacy is comparable, because sometimes ADEs are dose related. For example, higher doses of atypical antipsychotics were shown to cause more Parkinsonism in older adults than did lower-dosed treatment. ${ }^{127}$ Doses should be titrated up carefully from a low starting dose in patients where pharmacodynamic or pharmacokinetic sensitivity are likely to be concerns. In certain cases, therapeutic monitoring of plasma drug concentrations may be an aid to treatment, such as for hypothyroidism. ${ }^{128}$ However, clinical judgment is also essential in titrating drug dosages.

The prescriber should pay particular attention to avoid combinations that demonstrate known additional or synergistic toxic effects (eg, two medications with anticholinergic activity). Additionally, when multiple medications are required, such as in HIV-infected individuals, a dosing
Table 2 General considerations for managing polypharmacy in older adults

- Throughout medication history

- "Brown Bag" asking patient to bring in all prescription, OTC, and herbal medications

- "Teach-back" method, patient shows how taking medication

- Determine patient adherence to medication and barriers if not adherent

- Is the patient forgetting to take?

- Is the pill difficult to take?

- Is the pill costly?

- Does the patient believe that the drug is not needed?

- Where possible use the same pharmacy

- Indications for current medications

- Determine if medication is on Beers List or Medication

Appropriateness Index

- Is the dosage correct?

- Review drug-drug interactions

- Determine the therapeutic ratio

- Start low and go slow for titration up

- Good communication with other healthcare providers (physicians and caregivers)

Abbreviation: OTC, over-the-counter.

schedule should be established to clarify times of medication administration. Current evidence suggests that more efforts are needed to ensure patients receive clear and consistent information supporting safe medication use. ${ }^{129,130}$

Sometimes simplicity is the best solution. It may be ideal to have as few physicians as needed to address a patient's care. This move to better integrate care can help with managing polypharmacy as well as providing nonconflicting and good communications between health care providers and caregivers. A work group comprising leading researchers and clinicians across the country was formed as part of the HIV and Aging Consensus Project. The aim of this project was to recommend treatment strategies for clinicians who manage HIV-infected older adults. To address the above-mentioned concern, this work group recommended that individuals use either only one pharmacy or a pharmacy with an integrated computer network, and if possible, use a HIV-specialty pharmacy. ${ }^{131}$ Having a clinical pharmacist assist with prescriptions can help to reduce inappropriate prescribing and thereby decrease the rate of drug-related problems. ${ }^{132,133}$ Another method that may be helpful in managing the complex challenge of polypharmacy in HIV-infected older adults is the development of a clinic for HIV-infected patients over 50 years of age comparable to that developed in London. ${ }^{134}$

\section{Conclusion}

Over the last few decades, the number of HIV-infected older adults has increased significantly. Older patients 
with HIV-infection have several comorbidities requiring multiple pharmacotherapies that can increase their risk of polypharmacy and related adverse events. However, little is known about the impact of aging on medication use in HIV-infected older individuals, the potential for interactions with HAART and administered medications, and the impact of this on therapy tolerability and virological response with aging. Reducing pill burden, careful titration of medications, and increasing awareness of common DDIs can prevent coadministration of potentially harmful combinations and reduce unnecessary polypharmacy-related adverse events in this population. More studies need to be conducted to assess the long-term safety and efficacy of HAART in older adults with HIV infection.

\section{Acknowledgments}

The University of Rochester CTSA award KL2 RR024136 funded this work.

\section{Disclosure}

The authors report no conflict of interest in this work. The sponsor had no role in this work.

\section{References}

1. Antiretroviral Therapy Cohort Collaboration. Life expectancy of individuals on combination antiretroviral therapy in high-income countries: a collaborative analysis of 14 cohort studies. Lancet. 2008; 372(9635):293-299.

2. Effros RB, Fletcher CV, Gebo K, et al. Aging and infectious diseases: workshop on HIV infection and aging: what is known and future research directions. Clin Infect Dis. 2008;47(4):542-553.

3. Shah SS, McGowan JP, Smith C, Blum S, Klein RS. Comorbid conditions, treatment, and health maintenance in older persons with human immunodeficiency virus infection in New York City. Clin Infect Dis. 2002;35(10):1238-1243.

4. Simone MJ, Appelbaum J. HIV in older adults. Geriatrics. 2008; 63(12):6-12.

5. Goulet JL, Fultz SL, Rimland D, et al. Aging and infectious diseases: do patterns of comorbidity vary by HIV status, age, and HIV severity? Clin Infect Dis. 2007;45(12):1593-1601.

6. Gebo KA. Epidemiology of HIV and response to antiretroviral therapy in the middle aged and elderly. Aging Health. 2008;4(6):615-627.

7. Bushardt RL, Jones KW. Nine key questions to address polypharmacy in the elderly. JAAPA. 2005;18(5):32-37.

8. Hajjar ER, Cafiero AC, Hanlon JT. Polypharmacy in elderly patients. Am J Geriatr Pharmacother. 2007;5(4):345-351.

9. Hanlon JT, Schmader KE, Ruby CM, Weinberger M. Suboptimal prescribing in older inpatients and outpatients. $J$ Am Geriatr Soc. 2001;49(2):200-209.

10. Bushardt RL, Massey EB, Simpson TW, Ariail JC, Simpson KN. Polypharmacy: misleading, but manageable. Clin Interv Aging. 2008;3(2):383-389.

11. Kaufman DW, Kelly JP, Rosenberg L, Anderson TE, Mitchell AA. Recent patterns of medication use in the ambulatory adult population of the United States: the Slone survey. JAMA. 2002;287(3):337-344.

12. Freeland KN, Thompson AN, Zhao Y, Leal JE, Mauldin PD, Moran WP. Medication use and associated risk of falling in a geriatric outpatient population. Ann Pharmacother. 2012;46(9):1188-1192.
13. Zhan C, Sangl J, Bierman AS, et al. Potentially inappropriate medication use in the community-dwelling elderly: findings from the 1996 Medical Expenditure Panel Survey. JAMA. 2001;286(22): 2823-2829.

14. Fialová D, Topinková E, Gambassi G, et al; for AdHOC Project Research Group. Potentially inappropriate medication use among elderly home care patients in Europe. JAMA. 2005;293(11):1348-1358.

15. Buajordet I, Ebbesen J, Erikssen J, Brørs O, Hilberg T. Fatal adverse drug events: the paradox of drug treatment. J Intern Med. 2001;250(4): 327-341.

16. Nolan L, O'Malley K. Prescribing for the elderly. Part I: sensitivity of the elderly to adverse drug reactions. J Am Geriatr Soc. 1988;36(2): 142-149.

17. Budnitz DS, Lovegrove MC, Shehab N, Richards CL. Emergency hospitalizations for adverse drug events in older Americans. $N$ Engl $J$ Med. 2011;365(21):2002-2012.

18. Lazarou J, Pomeranz BH, Corey PN. Incidence of adverse drug reactions in hospitalized patients: a meta-analysis of prospective studies. JAMA. 1998;279(15):1200-1205.

19. Shorr RI, Ray WA, Daugherty JR, Griffin MR. Incidence and risk factors for serious hypoglycemia in older persons using insulin or sulfonylureas. Arch Intern Med. 1997;157(15):1681-1686.

20. Björkman IK, Fastbom J, Schmidt IK, Bernsten CB; for Pharmaceutical Care of the Elderly in Europe Research (PEER) Group. Drug-drug interactions in the elderly. Ann Pharmacother. 2002;36(11): 1675-1681.

21. Gurwitz JH, Field TS, Harrold LR, et al. Incidence and preventability of adverse drug events among older persons in the ambulatory setting. JAMA. 2003;289(9):1107-1116.

22. Field TS, Gurwitz JH, Harrold LR, et al. Risk factors for adverse drug events among older adults in the ambulatory setting. JAm Geriatr Soc. 2004;52(8):1349-1354.

23. Jörgensen T, Johansson S, Kennerfalk A, Wallander MA, Svärdsudd K. Prescription drug use, diagnoses, and healthcare utilization among the elderly. Ann Pharmacother. 2001;35(9):1004-1009.

24. Lees J, Chan A. Polypharmacy in elderly patients with cancer: clinical implications and management. Lancet Oncol. 2011;12(13): 1249-1257.

25. Madden JM, Graves AJ, Zhang F, et al. Cost-related medication nonadherence and spending on basic needs following implementation of Medicare Part D. JAMA. 2008;299(16):1922-1928.

26. Federman AD, Adams AS, Ross-Degnan D, Soumerai SB, Ayanian JZ. Supplemental insurance and use of effective cardiovascular drugs among elderly medicare beneficiaries with coronary heart disease. JAMA. 2001;286(14):1732-1739.

27. Miller RR. Hospital admissions due to adverse drug reactions. A report from the Boston Collaborative Drug Surveillance Program. Arch Intern Med. 1974;134(2):219-223.

28. Rochon PA, Gurwitz JH. Optimising drug treatment for elderly people: the prescribing cascade. BMJ. 1997;315(7115):1096-1099.

29. Fu AZ, Jiang JZ, Reeves JH, et al. Potentially inappropriate medication use and healthcare expenditures in the US community-dwelling elderly. Med Care. 2007;45(5):472-476.

30. American Geriatrics Society 2012 Beers Criteria Update Expert Panel. American Geriatrics Society updated Beers Criteria for potentially inappropriate medication use in older adults. J Am Geriatr Soc. 2012;60(4):616-631.

31. Fick DM, Cooper JW, Wade WE, Waller JL, Maclean JR, Beers MH. Updating the Beers criteria for potentially inappropriate medication use in older adults: results of a US consensus panel of experts. Arch Intern Med. 2003;163(22):2716-2724.

32. Beers MH. Explicit criteria for determining potentially inappropriate medication use by the elderly. An update. Arch Intern Med. 1997; 157(14):1531-1536.

33. Beers MH, Ouslander JG, Rollingher I, Reuben DB, Brooks J, Beck JC. Explicit criteria for determining inappropriate medication use in nursing home residents. UCLA Division of Geriatric Medicine. Arch Intern Med. 1991;151(9):1825-1832. 
34. Hanlon JT, Schmader KE, Samsa GP, et al. A method for assessing drug therapy appropriateness. J Clin Epidemiol. 1992;45(10): 1045-1051.

35. Steinman MA, Landefeld CS, Rosenthal GE, Berthenthal D, Sen S, Kaboli PJ. Polypharmacy and prescribing quality in older people. J Am Geriatr Soc. 2006;54(10):1516-1523.

36. Ingersoll KS, Cohen J. The impact of medication regimen factors on adherence to chronic treatment: a review of literature. J Behav Med. 2008;31(3):213-224.

37. Marzolini C, Back D, Weber R, et al; for Swiss HIV Cohort Study Members. Ageing with HIV: medication use and risk for potential drug-drug interactions. J Antimicrob Chemother. 2011;66(9): 2107-2111.

38. Miller CD, El-Kholi R, Faragon JJ, Lodise TP. Prevalence and risk factors for clinically significant drug interactions with antiretroviral therapy. Pharmacotherapy. 2007;27(10):1379-1386.

39. Ammassari A, Murri R, Pezzotti P, et al; for AdICONA Study Group. Self-reported symptoms and medication side effects influence adherence to highly active antiretroviral therapy in persons with HIV infection. J Acquir Immune Defic Syndr. 2001;28(5):445-449.

40. Barclay TR, Hinkin CH, Castellon SA, et al. Age-associated predictors of medication adherence in HIV-positive adults: health beliefs, self-efficacy, and neurocognitive status. Health Psychol. 2007;26(1): 40-49.

41. Hinkin CH, Hardy DJ, Mason KI, et al. Medication adherence in HIVinfected adults: effect of patient age, cognitive status, and substance abuse. AIDS. 2004;18 Supp1 1:S19-S25.

42. Paterson DL, Swindells S, Mohr J, et al. Adherence to protease inhibitor therapy and outcomes in patients with HIV infection. Ann Intern Med 2000;133(1):21-30.

43. Liedtke MD, Rathbun RC. Warfarin-antiretroviral interactions. Ann Pharmacother. 2009;43(2):322-328.

44. de Maat MM, Ekhart GC, Huitema AD, Koks CH, Mulder JW, Beijnen JH. Drug interactions between antiretroviral drugs and comedicated agents. Clin Pharmacokinet. 2003;42(3): 223-282.

45. Fellay J, Marzolini C, Decosterd L, et al. Variations of CYP3 A activity induced by antiretroviral treatment in HIV-1 infected patients. Eur $J$ Clin Pharmacol. 2005;60(12):865-873.

46. Eagling VA, Back DJ, Barry MG. Differential inhibition of cytochrome P450 isoforms by the protease inhibitors, ritonavir, saquinavir and indinavir. Br J Clin Pharmacol. 1997;44(2):190-194.

47. Rhee MS, Greenblatt DJ. Pharmacologic consideration for the use of antiretroviral agents in the elderly. J Clin Pharmacol. 2008;48(10): 1212-1225.

48. Nachega JB, Hsu AJ, Uthman OA, Spinewine A, Pham PA. Antiretroviral therapy adherence and drug-drug interactions in the aging HIV population. AIDS. 2012;26 Suppl 1:S39-S53.

49. Klotz U. Pharmacokinetics and drug metabolism in the elderly. Drug Metab Rev. 2009;41(2):67-76.

50. Sitar DS. Aging issues in drug disposition and efficacy. Proc West Pharmacol Soc. 2007;50:16-20.

51. Marchesini G, Bua V, Brunori A, et al. Galactose elimination capacity and liver volume in aging man. Hepatology. 1988;8(5): 1079-1083.

52. Wynne HA, Cope LH, Mutch E, Rawlins MD, Woodhouse KW, James OF. The effect of age upon liver volume and apparent liver blood flow in healthy man. Hepatology. 1989;9(2):297-301.

53. Manfredi R. HIV infection and advanced age emerging epidemiological, clinical, and management issues. Ageing Res Rev. 2004;3(1): 31-54.

54. Sulkowski MS. Drug-induced liver injury associated with antiretroviral therapy that includes HIV-1 protease inhibitors. Clin Infect Dis. 2004; 38 Suppl 2:S90-S97.

55. Clark WF, Sontrop JM, Macnab JJ, et al. Urine volume and change in estimated GFR in a community-based cohort study. Clin J Am Soc Nephrol. 2011;6(11):2634-2641.
56. Gupta SK, Eustace JA, Winston JA, et al. Guidelines for the management of chronic kidney disease in HIV-infected patients: recommendations of the HIV Medicine Association of the Infectious Diseases Society of America. Clin Inf Dis. 2005;40(11):1559-1585.

57. Choi AI, Rodriguez RA, Bacchetti P, Bertenthal D, Volberding PA, O'Hare AM. Racial differences in end-stage renal disease rates in HIV infection versus diabetes. J Am Soc Nephrol. 2007;18(11): 2968-2974.

58. Mocroft A, Kirk O, Gatell J, et al. Chronic renal failure among HIV-1infected patients. AIDS. 2007;21(9):1119-1127.

59. Scherzer R, Estrella M, Li Y, et al. Association of tenofovir exposure with kidney disease risk in HIV infection. AIDS. 2012;26(7): $867-875$.

60. Kalayjian RC, Franceschini N, Gupta SK, et al. Suppression of HIV-1 replication by antiretroviral therapy improves renal function in persons with low CD4 cell counts and chronic kidney disease. AIDS. 2008;22(4): $481-487$.

61. Cohen C, Elion R, Ruane P, et al. Randomized, phase 2 evaluation of two single-tablet regimens elvitegravir/cobicistat/emtricitabine/ tenofovir disoproxil fumarate versus efavirenz/emtricitabine/tenofovir disoproxil fumarate for the initial treatment of HIV infection. AIDS. 2011;25(6):F7-F12.

62. Elion R, Cohen C, Gathe J, et al; for GS-US-216-0105 Study Team. Phase 2 study of cobicistat versus ritonavir each with once-daily atazanavir and fixed-dose emtricitabine/tenofovir df in the initial treatment of HIV infection. AIDS. 2011;25(15):1881-1886.

63. Worm SW, Sabin C, Weber R, et al. Risk of myocardial infarction in patients with HIV infection exposed to specific individual antiretroviral drugs from the 3 major drug classes: the data collection on adverse events of anti-HIV drugs (D:A:D) study. J Infect Dis. 2010;201(3): $318-330$.

64. Seaberg EC, Muñoz A, Lu M, et al; for Multicenter AIDS Cohort Study. Association between highly active antiretroviral therapy and hypertension in a large cohort of men followed from 1984 to 2003. AIDS. 2005;19(9):953-960.

65. Sattler FR, Qian D, Louie S, et al. Elevated blood pressure in subjects with lipodystrophy. AIDS. 2001;15(15):2001-2010.

66. Hadigan C, Meigs JB, Corcoran C, et al. Metabolic abnormalities and cardiovascular disease risk factors in adults with human immunodeficiency virus infection and lipodystrophy. Clin Infect Dis. 2001;32(1): $130-139$.

67. Glesby MJ, Aberg JA, Kendall MA, et al; for Adult AIDS Clinical Trials Group A5159 Protocol Team. Pharmacokinetic interactions between indinavir plus ritonavir and calcium channel blockers. Clin Pharmacol Ther. 2005;78(2):143-153.

68. AIDSinfo. Guidelines for the use of antiretroviral agents in HIV-1 infected adults and adolescents [webpage on the Internet]. Rockville, MD: Department of Health and Human Services; 2013. Available from: http://aidsinfo.nih.gov/guidelines. Accessed 27 Feb, 2013.

69. Cheng JW, Rybak I. Use of digoxin for heart failure and atrial fibrillation in elderly patients. Am J Geriatr Pharmacother. 2010;8(5): 419-427.

70. Koup JR, Greenblatt DJ, Jusko WJ, Smith TW, Koch-Weser J. Pharmacokinetics of digoxin in normal subjects after intravenous bolus and infusion doses. J Pharmacokinet Biopharm. 1975;3(3): 181-192.

71. Schmitt C, Kaeser B, Riek M, Bech N, Kreuzer C. Effect of saquinavir/ ritonavir on $\mathrm{P}$-glycoprotein activity in healthy volunteers using digoxin as a probe. Int J Clin Pharmacol Ther. 2010;48(3):192-199.

72. Knoell KR, Young TM, Cousins ES. Potential interaction involving warfarin and ritonavir. Ann Pharmacother. 1998;32(12): 1299-1302.

73. Kamin DS, Grinspoon SK. Cardiovascular disease in HIV-positive patients. AIDS. 2005;19(7):641-652.

74. Dubé MP, Cadden JJ. Lipid metabolism in treated HIV Infection. Best Prac Res Clin Endocrinol Metab. 2011;25(3):429-442. 
75. Dubé MP, Stein JH, Aberg JA, et al; for Adult AIDS Clinical Trials Group Cardiovascular Subcommittee; HIV Medical Association of the Infectious Diseases Society of America. Guidelines for the evaluation and management of dyslipidemia in human immunodeficiency virus (HIV)-infected adults receiving antiretroviral therapy: recommendations of the HIV Medical Association of the Infectious Disease Society of America and the Adult AIDS Clinical Trials Group. Clin Infect Dis. 2003;37(5):613-627.

76. Samineni D, Desai PB, Sallans L, Fichtenbaum CJ. Steady-state pharmacokinetic interactions of darunavir/ritonavir with lipid-lowering agent rosuvastatin. J Clin Pharm. 2012;52(6):922-931.

77. Aquilante CL, Kiser JJ, Anderson PL, et al. Influence of SLCO1B1 polymorphisms on the drug-drug interaction between darunavir/ ritonavir and pravastatin. J Clin Pharm. 2012;52(11):1725-1738.

78. Gerber JG, Rosenkranz SL, Fichtenbaum CJ, et al; for AIDS Clinical Trials Group A5108 Team. Effect of efavirenz on the pharmacokinetics of simvastatin, atorvastatin, and pravastatin: results of AIDS Clinical Trials Group 5108 Study. J Acquir Immune Defic Syndr. 2005;39(3): 307-312.

79. Garraway WM, Collins GN, Lee RJ. High prevalence of benign prostatic hypertrophy in the community. Lancet. 1991;338(8765):469-471.

80. Berry SJ, Coffey DS, Walsh PC, Ewing LL. The development of human benign prostatic hyperplasia with age. J Urol. 1984;132(3): 474-479.

81. Kirby RS. The natural history of benign prostatic hyperplasia: what have we learned in the last decade? Urology. 2000;56(5 Suppl 1):3-6.

82. Franco-Salinas G, de la Rosette JJ, Michel MC. Pharmacokinetics and pharmacodynamics of tamsulosin in its modified-release and oral controlled absorption system formulations. Clinical Pharmacokinet. 2010;49(3):177-188.

83. Lallemand F, Salhi Y, Linard F, Giami A. Rozenbaum W. Sexual dysfunction in 156 ambulatory HIV-infected men receiving highly active antiretroviral therapy combinations with and without protease inhibitors. J Acquir Immune Defic Syndr. 2002;30(2):187-190.

84. Corona G, Razzoli E, Forti G, Maggi M. The use of phosphodiesterase 5 inhibitors with concomitant medications. J Endocrinol Invest. 2008;31(9):799-808.

85. Gur S, Kadowitz PJ, Gokce A, Sikka SC, Lokman U, Hellstrom WJ. Update on drug interactions with phosphodiesterase-5 inhibitors prescribed as first-line therapy for patients with erectile dysfunction or pulmonary hypertension. Curr Drug Metab. 2013;14(2): 265-269.

86. Nkuize M, De Wit S, Muls V, Arvanitakis M, Buset M. Upper gastrointestinal endoscopic findings in the era of highly active antiretroviral therapy. HIV Med. 2010;11(6):412-417.

87. Wang X, Boffito M, Zhang J, et al. Effects of the H2-receptor antagonist famotidine on the pharmacokinetics of atazanavir-ritonavir with or without tenofovir in HIV-infected patients. AIDS Patient Care STDS. 2011;25(9):509-515.

88. Luber AD, Brower R, Kim D, Silverman R, Peloquin CA, Frank I. Steady-state pharmacokinetics of once-daily fosamprenavir/ritonavir and atazanavir/ritonavir alone and in combination with $20 \mathrm{mg}$ omeprazole in healthy volunteers. HIV Med. 2007;8(7):457-464.

89. Winston A, Back D, Fletcher C, et al. Effect of omeprazole on the pharmacokinetics of saquinavir-500 $\mathrm{mg}$ formulation with ritonavir in healthy male and female volunteers. AIDS. 2006;20(10): 1401-1406.

90. Lyness JM, Caine ED, King DA, Cox C, Yoediono Z. Psychiatric disorders in older primary care patients. J Gen Intern Med. 1999;14(4): 249-254.

91. Ciesla JA, Roberts JE. Meta-analysis of the relationship between HIV infection and risk for depressive disorders. Am J Psychiatry. 2001;158(5):725-730.

92. Caballero J, Nahata MC. Use of selective serotonin-reuptake inhibitors in the treatment of depression in adults with HIV. Ann Pharmacother. 2005;39(1):141-145.
93. Elliott AJ, Uldall KK, Bergam K, Russo J, Claypoole K, Roy-Byrne PP. Randomized, placebo-controlled trial of paroxetine versus imipramine in depressed HIV-positive outpatients. Am J Psychiatry. 1998;155(3): $367-372$.

94. van der Lee MJ, Blenke AA, Rongen GA, et al. Interaction study of the combined use of paroxetine and fosamprenavir-ritonavir in healthy subjects. Antimicrob Agents Chemother. 2007;51(11):4098-4104.

95. Greenblatt DJ, von Moltke LL, Harmatz JS, et al. Short-term exposure to low-dose ritonavir impairs clearance and enhances adverse effects of trazodone. J Clin Pharmacol. 2003;43(4):414-422.

96. Hogeland GW, Swindells S, McNabb JC, Kashuba AD, Yee GC, Lindley CM. Lopinavir/ritonavir reduces bupropion plasma concentrations in healthy subjects. Clin Pharmacol Ther. 2007;81(1):69-75.

97. Merry C, Mulcahy F, Barry M, Gibbons S, Back D. Saquinavir interaction with midazolam: pharmacokinetic considerations when prescribing protease inhibitors for patients with HIV disease. AIDS. 1997;11(2):268-269.

98. Schmitt C, Hofmann C, Riek M, Patel A, Zwanziger E. Effect of saquinavir-ritonavir on cytochrome P450 3 A4 activity in healthy volunteers using midazolam as a probe. Pharmacotherapy. 2009;29(10): $1175-1181$.

99. Brackett CC. Severe prolonged sedation associated with coadministration of protease inhibitors and intravenous midazolam during bronchoscopy: a commentary. Pharmacotherapy. 2013;33(5):e85-e86.

100. Greenblatt DJ, von Moltke LL, Daily JP, Harmatz JS, Shader RI. Extensive impairment of triazolam and alprazolam clearance by shortterm low-dose ritonavir: the clinical dilemma of concurrent inhibition and induction. J Clin Psychopharmacol. 1999;19(4):293-296.

101. Owens RC Jr. QT prolongation with antimicrobial agents: understanding the significance. Drugs. 2004;64(10):1091-1124.

102. Owens RC Jr, Nolin TD. Antimicrobial-associated QT interval prolongation: pointes of interest. Clin Infect Dis. 2006;43(12): 1603-1611.

103. Baciewicz AM, Chrisman CR, Finch CK, SelfTH. Update on rifampin, rifabutin, and rifapentine drug interactions. Curr Med Res Opin. 2013;29(1):1-12.

104. De Ponti F, Poluzzi E, Cavalli A, Recanatini M, Montanaro N. Safety of non-antiarrhythmic drugs that prolong the QT interval or induce torsade de pointes: an overview. Drug Saf. 2002;25(4):263-286.

105. Krishna G, Moton A, Ma L, Martinho M, Seiberling M, McLeod J. Effects of oral posaconazole on the pharmacokinetics of atazanavir alone and with ritonavir or with efavirenz in healthy adult volunteers. J Acquir Immune Defic Syndr. 2009;51(4):437-444.

106. Yoganathan K, David L, Williams C, Jones K. Cushing's syndrome with adrenal suppression induced by inhaled budesonide due to a ritonavir drug interaction in a woman with HIV infection. Intl J STD AIDS. 2012;23(7):520-521.

107. Frankel JK, Packer CD. Cushing's syndrome due to antiretroviralbudesonide interaction. Ann Pharmacother. 2011;45(6):823-824.

108. Penzak SR, Formentini E, Alfaro RM, Long M, Natarajan V, Kovacs J. Prednisolone pharmacokinetics in the presence and absence of ritonavir after oral prednisone administration to healthy volunteers. $J$ Acquir Immune Defic Syndr. 2005;40(5):573-580.

109. Nieminen TH, Hagelberg NM, Saari TI, et al. Oxycodone concentrations are greatly increased by the concomitant use of ritonavir or lopinavir/ritonavir. Eur J Clin Pharmacol. 2010;66(10):977-985.

110. Clarke S, Mulcahy F, Bergin C, et al. Absence of opioid withdrawal symptoms in patients receiving methadone and the protease inhibitor lopinavir-ritonavir. Clin Infect Dis. 2002;34(8):1143-1145.

111. Bart PA, Rizzardi PG, Gallant S, et al. Methadone blood concentrations are decreased by the administration of abacavir plus amprenavir. Ther Drug Monit. 2001;23(5):553-555.

112. Sekar V, Tomaka F, Lefebvre E, et al. Pharmacokinetic interactions between darunavir/ritonavir and opioid maintenance therapy using methadone or buprenorphine/naloxone. J Clin Pharmacol. 2011;51(2): 271-278. 
113. Jamois C, Smith P, Morrison R, et al. Effect of saquinavir/ritonavir $(1000 / 100 \mathrm{mg}$ bid) on the pharmacokinetics of methadone in opiatedependent HIV-negative patients on stable methadone maintenance therapy. Addict Biol. 2009;14(3):321-327.

114. Brown TT, Qaqish RB. Antiretroviral therapy and the prevalence of osteopenia and osteoporosis: a meta-analytic review. AIDS. 2006;20(17):2165-2174.

115. Walker Harris V, Brown TT. Bone loss in the HIV-infected patient: evidence, clinical implications, and treatment strategies. J Infect Dis. 2012;205 Suppl 3:S391-S398.

116. Torti C, Mazziotti G, Soldini PA, et al. High prevalence of radiological vertebral fractures in HIV-infected males. Endocrine. 2012;41(3): $512-517$.

117. Young B, Dao CN, Buchacz K, Baker R, Brooks JT; for HIV Outpatient Study (HOPS) Investigators. Increased rates of bone fracture among HIV-infected persons in the HIV Outpatient Study (HOPS) compared with the US general population, 2000-2006. Clin Infect Dis. 2011;52(8):1061-1068.

118. Bolland MJ, Grey AB, Horne AM, et al. Annual zoledronate increases bone density in highly active antiretroviral therapy-treated human immunodeficiency virus-infected men: a randomized controlled trial. J Clin Endocrinol Metab. 2007;92(4):1283-1288.

119. Rozenberg S, Lanoy E, Bentata M, et al; for ANRS 120 Fosivir Study Group. Effect of alendronate on HIV-associated osteoporosis: a randomized, double-blind, placebo-controlled, 96-week trial (ANRS 120). AIDS Res Hum Retroviruses. 2012;28(9):972-980.

120. Beers MH, Dang J, Hasegawa J, Tamai IY. Influence of hospitalization on drug therapy in the elderly. J Am Geriatr Soc. 1989;37(8):679-683.

121. Bedell SE, Jabbour S, Goldberg R, et al. Discrepancies in the use of medications: their extent and predictors in an outpatient practice. Arch Intern Med. 2000;160(14):2129-2134.

122. Wilson IB, Schoen C, Neuman P, et al. Physician-patient communication about prescription medication nonadherence: a 50-state study of America's seniors. J Gen Intern Med. 2007;22(1):6-12.

123. Bayoumi I, Howard M, Holbrook AM, Schabort I. Interventions to improve medication reconciliation in primary care. Ann Pharmacother. 2009;43(10):1667-1675.
124. Steinman MA, Hanlon JT. Managing medications in clinically complex elders: "There's got to be a happy medium". JAMA. 2010;304(14): 1592-1601.

125. Osterberg L, Blaschke T. Adherence to medication. $N$ Eng J Med. 2005;353(5):487-497.

126. Boyd CM, Darer J, Boult C, Fried LP, Boult L, Wu AW. Clinical practice guidelines and quality of care for older patients with multiple comorbid disease: implications for pay for performance. JAMA. 2005;294(6):716-724.

127. Rochon PA, Stukel TA, Sykora K, et al. Atypical antipsychotics and parkinsonism. Arch Int Med. 2005;165(16):1882-1888.

128. Clarke N, Kabadi UM. Optimizing treatment of hypothyroidism. Treat Endocrinol. 2004;3(4):217-221.

129. Wolf MS, Shekelle P, Choudhry NK, Agnew-Blais J, Parker RM, Shrank WH. Variability in pharmacy interpretations of physician prescriptions. Med Care. 2009;47(3):370-373.

130. Wolf MS, Curtis LM, Waite K, et al. Helping patients simplify and safely use complex prescription regimens. Arch Intern Med. 2011;171(4):300-305.

131. Work Group for HIV and Aging Consensus Panel. Summary report from the Human Immunodeficiency Virus and Aging Consensus Project: treatment strategies for clinicians managing older individuals with the human immunodeficiency virus. J Am Geriatr Soc. 2012;60(5):974-979.

132. Hanlon JT, Weinberger M, Samsa GP, et al. A randomized, controlled trial of a clinical pharmacist intervention to improve inappropriate prescribing in elderly outpatients with polypharmacy. Am $\mathrm{J} \mathrm{Med}$. 1996;100(4):428-437.

133. Vinks TH, Egberts TC, de Lange TM, de Koning FH. Pharmacistbased medication review reduces potential drug-related problems in the elderly: the SMOG controlled trial. Drugs Aging. 2009;26(2): 123-133.

134. Waters L, Patterson B, Scourfield A, et al. A dedicated clinic for HIV-positive individuals over 50 years of age: a multidisciplinary experience. Int J STD AIDS. 2012;23(8):546-552.

135. Edmunds-Ogbuokiri J. Clinically significant drug interactions in the HIV-infected elderly. HIV Clin. 2011;23(2):12-15.
Clinical Interventions in Aging

\section{Publish your work in this journal}

Clinical Interventions in Aging is an international, peer-reviewed journal focusing on evidence-based reports on the value or lack thereof of treatments intended to prevent or delay the onset of maladaptive correlates of aging in human beings. This journal is indexed on PubMed Central, MedLine, the American Chemical Society's 'Chemical Abstracts

\section{Dovepress}

Service' (CAS), Scopus and the Elsevier Bibliographic databases. The manuscript management system is completely online and includes a very quick and fair peer-review system, which is all easy to use. Visit http://www.dovepress.com/testimonials.php to read real quotes from published authors. 